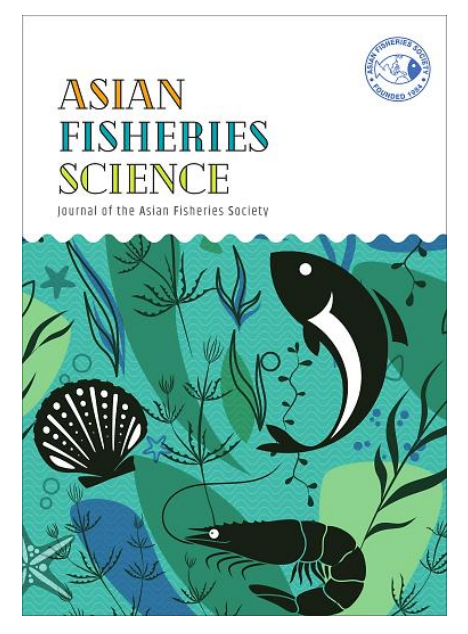

\title{
Determination of Short Mackerel Rastrelliger brachysoma (Bleeker, 1851) Stocks in the Gulf of Thailand Using Otolith Microchemistry
}

\author{
SONTAYA KOOLKALYA ${ }^{1}$, CLIVE TRUEMAN², AMONSAK SAWUSDEE ${ }^{3}$, TUANTONG JUTAGATE ${ }^{1, *}$ \\ ${ }^{1}$ Faculty of Agriculture, Ubon Ratchathani University, Warin Detudom Rd., Warinchamrab, Ubon Ratchathani 34190 , Thailand \\ ${ }^{2}$ National Oceanography Centre, University of Southampton, Southampton, United Kingdom of Great Britain and Northern Ireland \\ ${ }^{3}$ School of Science, Walailak University, Nakhonsithammarat, Thailand
}

*E-mail: tuantong.j@ubu.ac.th | Received: 17/09/2019; Accepted: 02/09/2020

(ㄷ) Asian Fisheries Society

ISSN: 0116-6514

E-ISSN: 2073-3720

https://doi.org/10.33997/j.afs.2020.33.3.006

\begin{abstract}
The short mackerel Rastrelliger brachysoma (Bleeker, 1851) is a commercially important fish in the Gulf of Thailand $(G o T)$. The management strategy for this species in the entire GoT is based on the single-stock approach, which may not be efficient or effective. This study aims to identify the stock structure of short mackerel in the GoT. A total of 55 samples of short mackerel were collected throughout the GoT, sexed, weighed and measured. The pair of sagittal otoliths were removed from individual fish. The left sagittae were used for stock identification via microchemistry elements. The microchemical composition of the otoliths from four locations (Eastern, Upper, Central and Lower GoT) was different (MANOVA, $P<0.01$ ) for both sexes. The linear discriminant function analysis (LDFA) using eight microchemical elements in the edge zone showed high classification accuracy of short mackerel with regard to their sampling location ( $89 \%$ for males and $79 \%$ for females). The LDFA results also showed high classification accuracy in both sexes (more than $85 \%$ ) and indicated that there were four short mackerel stocks in the GoT. The right sagittae, meanwhile, were used for fish ageing. Results showed that the adults had resided in the stock more than $50 \%$ of their life before being captured.
\end{abstract}

Keywords: otolith, microchemistry elements, linear discriminant function analysis

\section{Introduction}

The short mackerel, Rastrelliger brachysoma (Bleeker, 1851) is a tropical pelagic fish found both in estuarine and offshore areas, from the central Eastern Pacific Ocean throughout the west-central Atlantic Ocean (Collette and Nauen, 1983; Froese and Pauly, 2017). This species is widespread in South-east Asia and is highly abundant in the Gulf of Thailand (GoT), (Collette and Nauen, 1983). Short mackerel is a commercially important species, as well as common seafood. The fishery for short mackerel in the GoT has been developed since the 1950s, and the highest yield was observed in 1999 at 125,175 metric tons (Fishery Statistics Analysis and Research Group, 2016). Koolkalya et al. (2015) analysed the landings of short mackerel between 1984 and 2009 in the GoT and found an inverted trend in its yield as the landings continuously increased from 1984 to early 2000s and then started to decrease in 2004.
Due to the unstable and declining catches of short mackerel in the GoT, there are concerns about stock status. The present conservation measures for short mackerel in the GoT include an annual ban of fishing from mid-February to mid-May in the near-shore zone of the middle GoT (Fig. 1), which is reported to be a spawning ground. For fisheries management, the annual allowable catch and effort are determined for the whole GoT and assume a single stock of short mackerel (Department of Fisheries, 2014). However, to examine the effects of fishing on a fish population, and to devise an appropriate management plan in a marine ecosystem as vast as the GoT, it is necessary to understand the stocks of the target species, because each stock has its unique life history and response to fishing intensity (Conti et al., 2012; Methot and Wetzel, 2013; Morioka et al., 2019).

Many fisheries management programs have failed because they did not consider the differences among 
stocks of the target species in the study area (Begg et al., 1999). Stock identification could be applied to understand the population dynamics clearly, biological characteristics and productivity rates of a selected species, all of which are undoubtedly important for sustainable fishery management (Begg et al., 1999; Methot and Wetzel, 2013).

There are many techniques for determining fish stocks within a population; for example, morphometric and meristic characteristics, life history parameters, population genetics and tagging, as well as otolith analysis. Otoliths are crystalline structures composed of calcium carbonate contained in an endolymphatic sac of teleost fishes (Hong et al., 2019). The chemical composition of an otolith, considered a metabolically inert structure, is influenced by the physical and chemical properties of the environment (Elsdon et al., 2008). Different rates in the absorption of chemical elements by the otolith are controlled by both exogenous and endogenous factors, such as salinity, sex and growth (Sturrock et al., 2014). This metabolically inert property creates a temporal record of the fish's life history, and thus makes it possible to retrieve information on environmental conditions experienced by individual fish, from hatching until capture; hence, this structure can be used for identifying fish stocks (Campana, 2005; Tanner et al., 2012).

In this study, it is hypothesised that there are multiple stocks of short mackerel in the GoT. Therefore, we aim to identify the stock assembly of short mackerel in the GoT. Multivariate comparison of chemical element concentrations between primordium (core) and edge zones of the otolith was applied to discriminate the stocks within the population. Variation in elements in the otolith between males and females was also investigated. Moreover, individual fish were aged by counting the daily rings of the otolith to determine the age at recruitment and age at capture for estimating the time each fish resided in its stock before being caught.

\section{Materials and Methods}

\section{Fish sampling and otolith preparation}

Samples of short mackerel $R$. brachysoma were collected from sites in four major areas of the GoT, including the Eastern GoT (EGT), the Upper GoT (UGT), the Middle GoT (MGT), and the Lower GoT (LGT)(Fig. 1). The areas represent the major fishing grounds in the GOT, where the UGT is the most productive area, followed by the EGT, MGT and LGT. The samples were collected from the main landing sites in each area: Chanthaburi Province for EGT, Samutsakorn Province for UGT, Suratthani Province for MGT and Songkhla Province for LGT. Medium to large individuals, i.e. length > $100 \mathrm{~mm}$ TL (total length), were collected, which allowed comparison of otolith microchemistry between the core and the edge of each sample. Total length $(\mathrm{mm})$, body weight $(\mathrm{g})$ and sex of 55 individuals were recorded (Table 1).

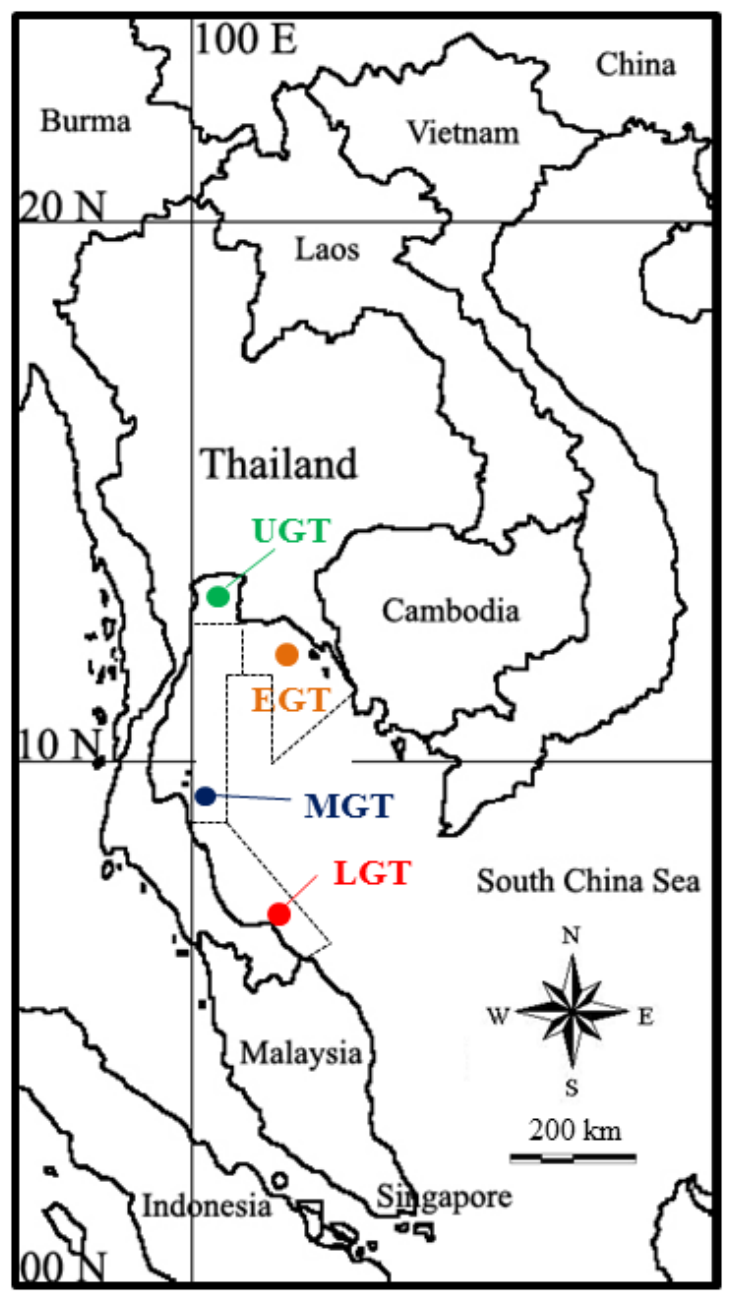

Fig. 1. Map of the Gulf of Thailand showing the sampling and landing sites to determine the stocks of short mackerel Rastrelliger brachysoma. UGT = Upper Gulf of Thailand, EGT = Eastern Gulf of Thailand, MGT = Middle Gulf of Thailand and LGT $=$ Lower Gulf of Thailand.

Table 1. Sampling locations, sex, mean and standard deviation (SD) of total length (TL, mm), and sample size ( $\mathrm{n}$ ) of Rastrelliger brachysoma in the Gulf of Thailand.

\begin{tabular}{|c|c|c|c|c|}
\hline \multirow{2}{*}{ Sampling location } & \multirow{2}{*}{ Sex } & \multicolumn{2}{|c|}{$\mathrm{TL}(\mathrm{mm})$} & \multirow{2}{*}{$\mathrm{n}$} \\
\hline & & Mean & SD & \\
\hline \multirow[t]{2}{*}{ Eastern Gulf of Thailand } & Male & 167 & 12 & 7 \\
\hline & Female & 185 & 3 & 9 \\
\hline \multirow[t]{2}{*}{ Upper Gulf of Thailand } & Male & 151 & 14 & 7 \\
\hline & Female & 185 & 8 & 8 \\
\hline \multirow[t]{2}{*}{ Middle Gulf of Thailand } & Male & 175 & 6 & 6 \\
\hline & Female & 187 & 2 & 6 \\
\hline \multirow[t]{2}{*}{ Lower Gulf of Thailand } & Male & 181 & 7 & 6 \\
\hline & Female & 184 & 4 & 6 \\
\hline
\end{tabular}


The pair of sagittal otoliths were removed from individual fish. Each sagitta was rinsed with water, cleaned of adhering tissue, dried and stored in plastic micro-centrifuge tubes. Each sagitta was embedded in epoxy resin and then cut through the mid-plane (i.e. a transverse section) by using a slow-speed diamond wheel saw (SBT650, South Bay Technology, USA), which continuously lubricated the sample with coolant solution. The sections were polished using silicon carbide paper (P2000 to P2500) and rinsed with distilled water until the primordium was seen. For each sample, the left sagitta was used for microelement analysis, while the right one was used for ageing.

\section{Otolith trace element microchemistry analysis}

The New Wave UP193FX laser ablation system coupled to a Thermo X-Series II inductively coupled plasma mass spectrometer (LA-ICP-MS, Thermo XSeries II ICP-MS) at the National Oceanography Centre, Southampton, UK, was used to measure the trace elements in 55 left otolith sections. The laser beam ( $35 \mu \mathrm{m}$ diameter) was set to spot the sectioned sagitta at $10 \mu \mathrm{m}$ increments, starting from the primordium and moving outwards to the dorsal edge. The analysis protocols followed Longmore et al. (2011). Briefly, a $10 \mathrm{~Hz}$ pulse rate for the laser ablation (i.e. ablating sagitta material) was set. Before and after each series of otolith transects, certified reference materials, the NIST 612 and 610 standards (Jochum and Stoll, 2008) were applied for calibration, using the same parameters for the sectioned otoliths. All data were internally normalised to calcium $\left({ }^{44} \mathrm{Ca}\right.$ )(Campana, 2005). The following elements were acquired: ${ }^{7} \mathrm{Li}$, ${ }^{24} \mathrm{Mg},{ }^{39} \mathrm{~K},{ }^{55} \mathrm{Mn},{ }^{60} \mathrm{Ni},{ }^{65} \mathrm{Cu},{ }^{88} \mathrm{Sr}$ and ${ }^{137} \mathrm{Ba}$. Data were processed using the standard sample bracketing technique, and the element concentrations detected in the otoliths were expressed relative to the concentration of calcium (Campana, 2005).

\section{Fish ageing}

For fish ageing, we first validated the formation of daily rings of otoliths in short mackerel larvae at ages of $3,5,12,15$ and 20 days by sampling 15 fish for each age. The larvae were artificially bred at Samutsakorn Coastal Aquaculture Research and Development Centre, Department of Fisheries of Thailand. Samples were kept in $80 \%$ ethanol and then the otoliths of these larvae were removed, whereby the daily rings were examined under light microscope $(40 \mathrm{X})$ to validate the daily increment deposition in otoliths.

Secondly, the age of each individual sample was estimated by using the right sagitta sections. The otolith sections were viewed through a compound microscope $(40 \mathrm{X})$ and photographed with a digital camera (ZEISS, AxioCam ERc 5s, Germany). The image was then used for daily ring counting by the program
ImageJ (Rasband, 2014). The age of individual fish was determined by the equations:

$\ln \left(\frac{d r}{d t}\right)=\alpha-\beta r+\varepsilon$

and

$\widehat{T}=\left(e^{\alpha} \beta\right)^{-1}\left(e^{\beta R}-1\right)$

where $d r$ is the distance along the selected counting transect; $d t$ is the number of daily rings within the selected counting transect; $r$ is the distance from otolith core to middle of the selected counting transect; $\alpha$ and $\beta$ are the coefficients of the regression equation; $\hat{T}$ is the age (days) of the individual fish; and $R$ is the total distance from the core to edge (Morales-Nin, 1992).

\section{Data analysis}

The obtained measurements for each element (element.Ca-1) were log $(x+1)$ transformed to achieve normality and homogeneity of variances. Multivariate analysis of variance (MANOVA) and analysis of variance (ANOVA) were used to examine variation in element concentrations among locations. Principal component analysis (PCA) was used to display the microchemistry data of the sectioned otolith (i.e. edge zone) to examine the relative importance of each variable to the sampling locations. Differences in otolith microchemistry between the core and the edge of the otoliths by sex were examined by t-test. Linear discriminant function analysis (LDFA) was used to classify individual fish to their collection locations using microchemistry values at the sagitta edge and average values from core to edge (i.e. whole otolith value). The elements used in LDFA ( $\mathrm{Li}^{\mathrm{CCa}}{ }^{-1}, \mathrm{Mg}^{\mathrm{C} \mathrm{Ca}^{-1}}$, $\mathrm{K} \cdot \mathrm{Ca}^{-1}, \mathrm{Mn} \cdot \mathrm{Ca}^{-1}, \mathrm{Sr} \cdot \mathrm{Ca}{ }^{-1}$ ) were incorporated with the elements commonly used for fish stock identification (Ni.Ca ${ }^{-1}, \mathrm{Cu} \mathrm{Ca}^{-1}$, and Ba.Ca ${ }^{-1}$ ) (Thresher et al., 1994; Proctor et al., 1995; Sturrock et al., 2012, 2014; Kang et al., 2014). Classification accuracy of the LDFA was evaluated by cross-validated classification success using a jackknife approach.

The sagitta microchemistry element concentrations at each spot, from the primordium toward the edge, were fed into LDFA functions. The values obtained for each individual fish were plotted along LDFA Axes 1 and 2, i.e. showing the changes in elemental profile from birth to death. The average values of the last three spots from each individual fish, in each zone and sex, were also fed into the LDFA. The minimum and maximum values for each LDFA axis were further used to illustrate the boundary of the adult stock ("box"). The distance in the otolith, from the primordium to the last spot outside the box, was measured to estimate the age at recruitment as shown in Equation 2. The percentage of time that each individual fish resided in its stock, i.e. 
percentage of residence, was calculated by:

$\%$ of residence $=$

$\left(\frac{\text { Age at capture-Age at recruitment }}{\text { Age at capture }}\right) \times 100$

\section{Results}

The structures of eight elements (Li.Ca-1, ${\mathrm{Mg} . \mathrm{Ca}^{-1}}^{-1}$, K.Ca ${ }^{-1},{\mathrm{Mn} . C a^{-1}, \mathrm{Ni} . \mathrm{Ca}^{-1}, \mathrm{Cu} . \mathrm{Ca}^{-1} \text {, Sr.Ca }}^{-1}$ and Ba.Ca ${ }^{-1}$ ) from otolith edge and primordium zones were analysed. By applying MANOVA, significant differences in the microchemical composition of the otolith edge were found among the collection locations in both sexes $(F=4.93, P<0.01$ for males; $F$ $=2.54, P<0.01$ for females). Significant differences in the microchemical composition of the otolith primordium among collection locations were also found in female samples, but not in male samples ( $F=$ $1.12, P=0.37$ for males; $F=2.59, P<0.01$ for females).
The ANOVA results showed that there were no statistical differences $(P>0.05)$ in the concentration of any of the elements at the primordium zone in male samples. Meanwhile, Mn.Ca ${ }^{-1}$ and $\mathrm{Ni}^{-\mathrm{Ca}^{-1}}$ were significantly different $(P<0.05)$ in the otolith core of

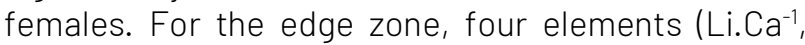
${\mathrm{Mn} . \mathrm{Ca}^{-1}}^{-1} \mathrm{Ni}_{\mathrm{CC}}{ }^{-1}$ and Sr.Ca ${ }^{-1}$ ) showed significant differences in male samples among collection locations $(P<0.05)$. Meanwhile, three elements

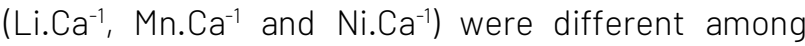
collection locations for females $(P<0.05$, Fig. 2). Among collection locations, for both sexes, the concentration of $\mathrm{Li}^{\mathrm{CC} \mathrm{Ca}^{-1}}$ was highest at LGT and lowest at UGT. The highest concentrations of $\mathrm{Mn}^{-\mathrm{Ca}^{-1}}$ and $\mathrm{Ni}^{-\mathrm{Ca}^{-1}}$ were found at UGT for both sexes. The concentration of Sr.Ca-1 was highest at MGT and lowest at UGT for male samples, with no difference in females (Fig. 2). The results also showed a significant difference in most of the microchemistry elements between the primordium and edge by sex, except for $\mathrm{Mn} . \mathrm{Ca}^{-1}$ and $\mathrm{Ba} \cdot \mathrm{Ca}^{-1}$ in male samples and $\mathrm{Ni}^{-\mathrm{Ca}^{-1}}$ in female samples (Table 2).

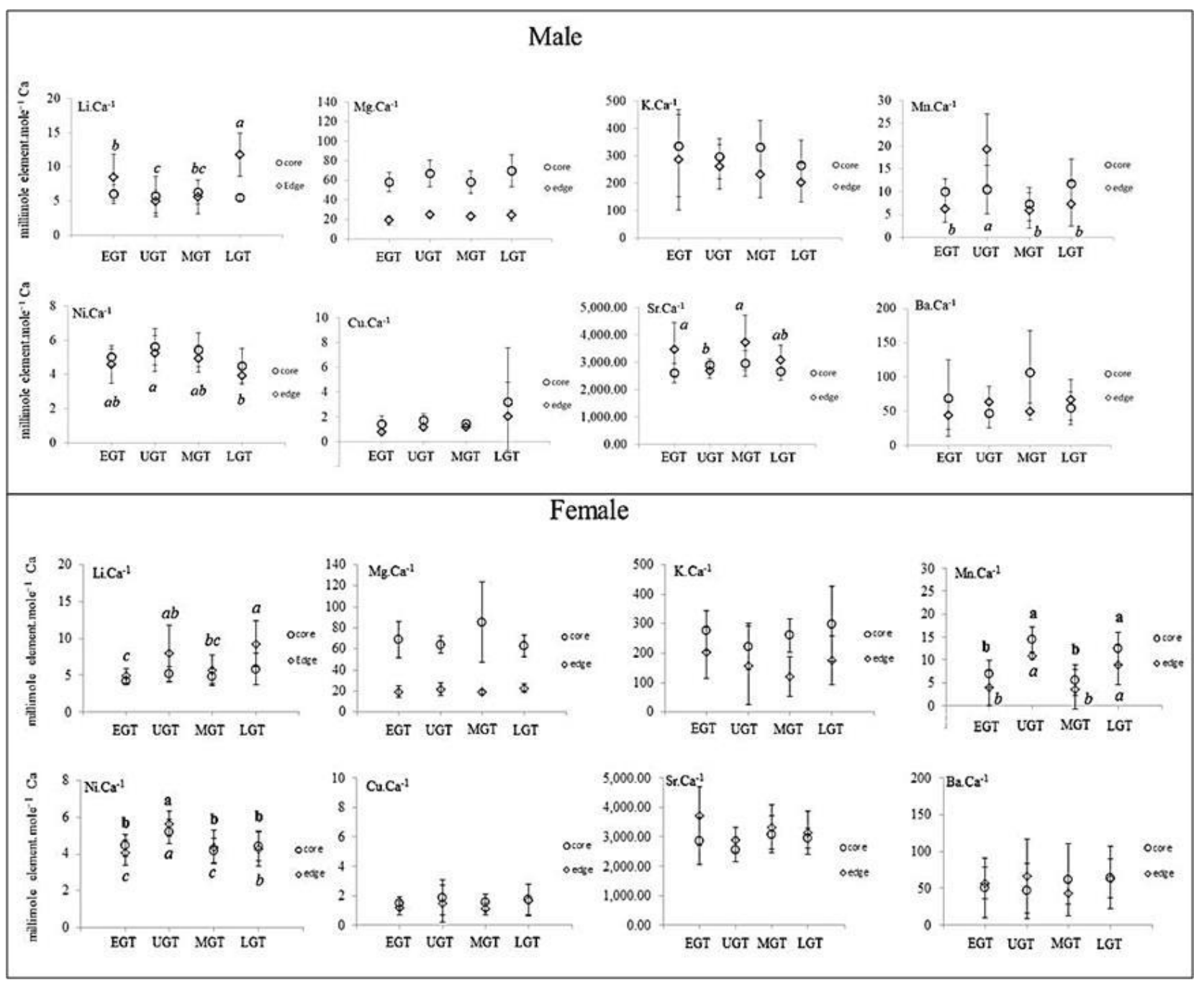

Fig. 2. Mean untransformed concentrations and standard deviations (SD) of trace elements to Ca ratios (millimole element. mole $^{-1} \mathrm{Ca}$ ) per sample location used in analysis. The values for the same element indicated with different letters are significantly different $(P<0.05)$. The bold and italic letters indicate concentrations at core and edge, respectively. EGT = Eastern Gulf of Thailand, UGT = Upper Gulf of Thailand, MGT = Middle Gulf of Thailand and LGT = Lower Gulf of Thailand. 
The PCA results (Fig. 3 ) indicated that the first two axes cumulatively explained $49.9 \%$ and $54.3 \%$ of microchemistry elements from the otolith edge zone among collection locations for males and females, respectively. For the male samples, both $\mathrm{PC}$ axes had high loadings for Sr.Ca-1 ${ }^{-1} \mathrm{Na} \cdot \mathrm{Ca}^{-1}$ and K.Ca ${ }^{-1}$. Meanwhile, for the females, Sr.Ca-1 had a high loading score in the first axis and Na.Ca ${ }^{-1}$ and $\mathrm{K} \mathrm{Ca}^{-1}$ were important for the second axis. Moreover, Li.Ca ${ }^{-1}$, Mg.Ca ${ }^{-1}$ and Mn.Ca ${ }^{-1}$ also showed significant loading scores for the two axes. A high loading score indicates that a particular variable (i.e. element) has a strong relationship to a particular principal component. These microchemistry elements, therefore, were further used in LDFA. In addition, Ni.Ca ${ }^{-1}, \mathrm{Cu} . \mathrm{Ca}^{-1}$ as well as $\mathrm{Ba} . \mathrm{Ca}^{-1}$, which are common elements for identifying a fish stock, were also used in LDFA to examine each sample's probability of membership to a stock.

Table 2. Mean untransformed concentrations and standard deviations (SD) of trace elements to Ca ratios (millimole element.mole $\mathrm{e}^{-1} \mathrm{Ca}$ ) for otolith primordium and edge in male and female Rastrelliger brachysoma in the Gulf of Thailand.

\begin{tabular}{|c|c|c|c|c|c|c|}
\hline \multirow{2}{*}{ Elements } & \multicolumn{2}{|l|}{ Male } & \multirow{2}{*}{$P$-value } & \multicolumn{2}{|l|}{ Female } & \multirow{2}{*}{ P-value } \\
\hline & Primordium & Edge & & Primordium & Edge & \\
\hline $\mathrm{Li}_{\mathrm{C}} \mathrm{Ca}^{-1}$ & $5.87 \pm 2.03$ & $7.60 \pm 4.01$ & $0.006^{* *}$ & $4.95 \pm 1.47$ & $6.82 \pm 3.44$ & $0.000^{* *}$ \\
\hline $\mathrm{Mg} \cdot \mathrm{Ca}^{-1}$ & $63.23 \pm 16.84$ & $22.49 \pm 5.26$ & $0.000 * *$ & $69.88 \pm 30.25$ & $20.75 \pm 5.56$ & $0.000^{* *}$ \\
\hline $\mathrm{K} \cdot \mathrm{Ca} \mathrm{a}^{-1}$ & $307.23 \pm 107.10$ & $247.12 \pm 120.80$ & $0.000^{* *}$ & $262.53 \pm 112.73$ & $167.24 \pm 101.01$ & $0.000^{* *}$ \\
\hline $\mathrm{Mn} \cdot \mathrm{Ca}^{-1}$ & $9.89 \pm 4.47$ & $9.93 \pm 8.90$ & $0.097^{n s}$ & $9.87 \pm 4.84$ & $6.76 \pm 5.02$ & $0.000^{* *}$ \\
\hline Ni.Ca $a^{-1}$ & $5.14 \pm 1.08$ & $4.68 \pm 1.03$ & $0.009 * *$ & $4.61 \pm 0.89$ & $4.63 \pm 1.08$ & $0.887^{\text {ns }}$ \\
\hline Cu.Ca-1 & $1.92 \pm 2.36$ & $1.25 \pm 1.34$ & $0.001^{* *}$ & $1.66 \pm 1.12$ & $1.35 \pm 1.29$ & $0.003^{* *}$ \\
\hline Sr.Ca $a^{-1}$ & $2,780.14 \pm 392.51$ & $3,221.95 \pm 893.81$ & $0.000^{* *}$ & $2,839.24 \pm 614.67$ & $3,284.53 \pm 882.91$ & $0.002^{* *}$ \\
\hline $\mathrm{Ba} \cdot \mathrm{Ca}^{-1}$ & $68.41 \pm 50.31$ & $55.81 \pm 31.91$ & $0.612^{\text {ns }}$ & $54.66 \pm 43.00$ & $57.96 \pm 35.05$ & $0.018^{*}$ \\
\hline
\end{tabular}

Data are presented as mean \pm SD; values in the same row with ${ }^{* *}$ are significantly different $(P<0.05)$; ns = non-significant $(P>$ $0.05)$ by using t-test.

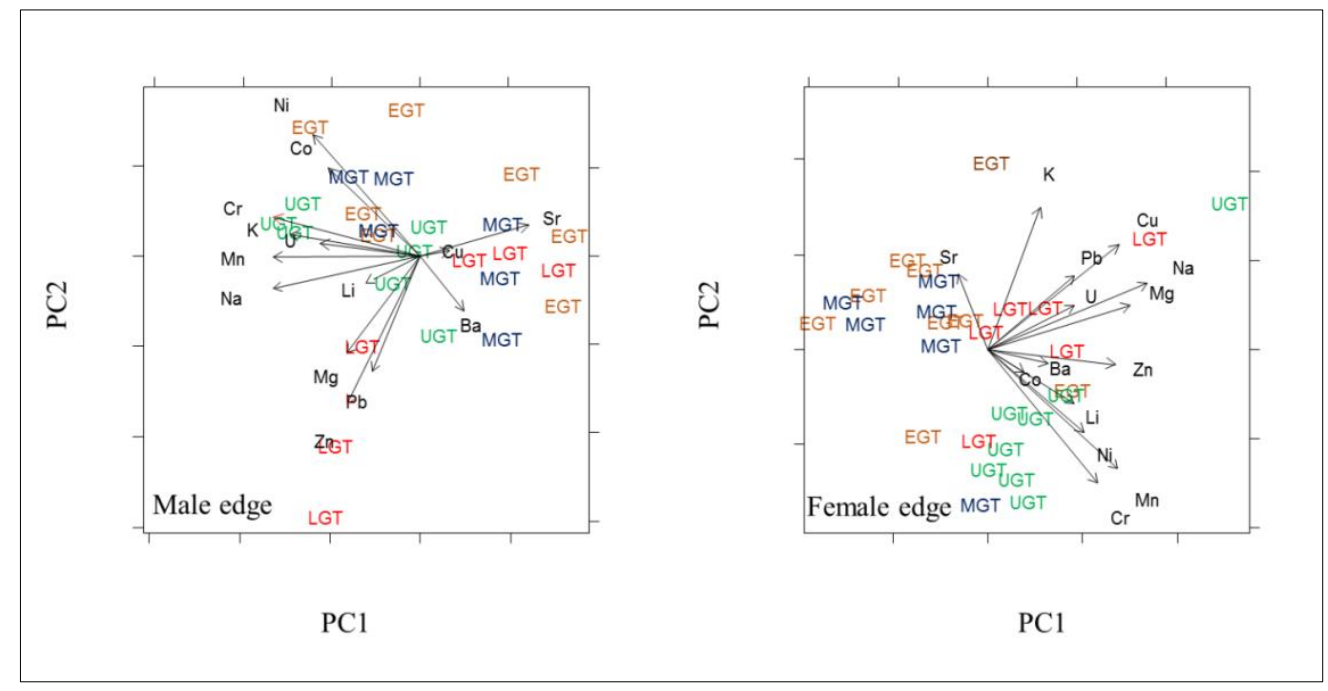

Fig. 3. PCA biplots of microchemistry element $(x)$ to Ca ratios $(x / C a)$ in the otolith edge of male and female Rastrelliger brachysoma in the Gulf of Thailand. Note: 1) Each abbreviation represents a fish sample, indicating its collected location and 2) The length of arrows approximates the variance of the elements, whereas the angles between them approximate their correlations.

The LDFA discrimination models, using microchemical composition (i.e. the eight elements described previously) of the edge zone of otoliths showed high classification accuracy of short mackerel to their collection locations. The overall classification accuracies of short mackerel to their collection locations were $89 \%$ for male samples and $86 \%$ for female samples (Table 3). This means that the profiles of microchemical elements of individual fish could be used to predict their collection location with high confidence, and clearly separated the samples into four groups. This indicates that there are four adult stocks of short mackerel, i.e. the Eastern of GoT, the Inner of GoT, the Middle of GoT and the Lower of GoT. Furthermore, the LDFA results, using the microchemical composition of the whole sagittae, also showed high classification accuracy in both sexes ( $85 \%$ and $86 \%$ for males and females, respectively) (Table 3), which confirmed the presence of four distinct stocks of short mackerel in the GoT. 
Table 3. Cross-validated classification results of LDFA of Rastrelliger brachysomain the Gulf of Thailand, Individuals were classified to a collection location based on the microchemistry signature of the otolith edge material (A) and the whole otolith (B). Values in bold represent percentage of individuals correctly classified to their collection location.

A: Microchemistry signature of the otolith edge.

\begin{tabular}{lllllllll}
\hline \multirow{2}{*}{ Collection location } & \multicolumn{7}{l}{ Male } & \multicolumn{4}{l}{ Female } \\
\cline { 2 - 9 } & \multicolumn{2}{l}{ Predicted group membership (\%) } & \multicolumn{2}{l}{ Predicted group membership (\%) } \\
\cline { 2 - 9 } & EGT & UGT & MGT & LGT & EGT & UGT & MGT & LGT \\
\hline EGT & 100 & 0 & 0 & 0 & 89 & 0 & 11 & 0 \\
UGT & 0 & 100 & 0 & 0 & 0 & 100 & 0 & 0 \\
MGT & 33 & 0 & 67 & 0 & 16.5 & 16.5 & 67 & 0 \\
LGT & 17 & 0 & 0 & 83 & 0 & 0 & 17 & 83 \\
\hline
\end{tabular}

B: Microchemistry signature of the whole otolith.

\begin{tabular}{lllllllll}
\hline \multirow{2}{*}{ Collection location } & \multicolumn{4}{l}{ Male } & \multicolumn{4}{l}{ Female } \\
\cline { 2 - 9 } & \multicolumn{2}{l}{ Predicted group membership (\%) } & \multicolumn{4}{l}{ Predicted group membership (\%) } \\
\cline { 2 - 9 } & EGT & UGT & MGT & LGT & EGT & UGT & MGT & LGT \\
\hline EGT & 86 & 0 & 14 & 0 & 89 & 11 & 0 & 0 \\
UGT & 0 & 100 & 0 & 0 & 0 & 88 & 0 & 12 \\
MGT & 17 & 0 & 83 & 0 & 0 & 17 & 83 & 0 \\
LGT & 17 & 17 & 0 & 67 & 17 & 0 & 0 & 83 \\
\hline
\end{tabular}

EGT = Eastern Gulf of Thailand, UGT = Upper Gulf of Thailand, MGT = Middle Gulf of Thailand and LGT = Lower Gulf of Thailand.

Daily ring formation was validated by the known age of larval samples (days), and compared to the number of counted rings in the otolith of each sample (15 larvae at each age); results confirmed that a ring was formed every day (Fig. 4). The mean age of the sampled individuals was less than one year, i.e. age at capture was less than 360 days (Table 4). By tracking the microchemistry elemental profile of individual fish, the portion within the box in Figure 5 represents the period of time that fish resided in the stock, while the portion outside the box represents the prerecruitment phase. The distance in otolith from primordium (represented by a triangle in Fig. 5), to the last spot displayed outside the box, was measured and the number of daily rings estimated. The age at recruitment ranged between 58 and 77 days (Table 4). The percentage residence of each stock was also calculated (Table 4). Results indicated that male and female R. brachysoma spent at least $63 \%$ and $83 \%$ of their life respectively, in their designated stock before being caught.

\section{Discussion}

Otolith microchemistry signatures have been widely used in marine ecology and fisheries science (Campana, 2005). In this study, both MANOVA and ANOVA results revealed significant differences in concentrations of elements within the otolith edge among collection sites in the GoT. The significant differences in the results can be explained by the distinct physiochemical properties of the GoT water as reported by Shazili et al. (1999) and Liu et al. (2016) in their studies on spatial variations in trace element concentrations in the GoT.
All microchemical elements used in this study showed high accuracy for identifying fish stocks, and low physiology bias because they are relatively unaffected by physiological controls of the fish (Thresher et al., 1994; Proctor et al., 1995; Sturrock et al., 2012, 2014). In the present study, among the selected elements, Sr.Ca ${ }^{-1}$ showed the highest concentration in the otoliths. The Sr.Ca- ${ }^{-1}$ in seawater is usually more enriched in the deep ocean than the surface water and coastal area (de Villiers, 1999). Therefore, the higher Sr.Ca-1 in the edge than core observed in the present study implies that the adult short mackerel inhabits more open and deeper water than the young individuals. Similarly, stock discrimination of many mackerel species in Australia conducted by using otolith microchemistry showed clear results in stock identification (Cameron and Begg, 2004). Distinct differences in Sr.Ca ${ }^{-1}, \mathrm{Ba} . \mathrm{Ca}^{-1}$ and $\mathrm{Li}^{-\mathrm{Ca}^{-1}}$ were also used to describe the population structure of the blue jack mackerel Trachurus picturatus (Bowdich, 1825) in the northeast Atlantic (Moreira et al., 2018).

The LDFA results in the present study also suggested the usefulness of otolith edge microchemistry for identifying the stocks of short mackerel in the GoT. Fish were classified with high accuracy to their collection locations, which indicates that there were at least four stocks of short mackerel in the GoT. Errors in assigning individuals to stock could be explained by a short residence time in the area prior to capture that was not sufficient to acquire the sitespecific signature. Alternatively, it may simply reflect that environmental conditions at the selected locations were not sufficiently distinct to generate a unique suite of element concentrations in fish 


\section{$1 \mathrm{~mm}$}

Fig. 4. General characteristics of 15-day-old Rastrelliger brachysoma larva (left) and validated otolith (right), with numbers indicating daily rings.

Table 4. Age at recruitment and percentage of residence of short mackerel Rastrelliger brachysoma stocks in the Gulf of Thailand.

\begin{tabular}{lllll}
\hline \multirow{2}{*}{ Collection location } & No. of & Average age (days) & \% of \\
\cline { 3 - 4 } & individuals & At capture & At recruitment & residence \\
\hline Eastern Gulf of Thailand & 16 & 263 & 66 & 75 \\
Upper Gulf of Thailand & 15 & 252 & 58 & 79 \\
Middle Gulf of Thailand & 12 & 256 & 77 & 61 \\
Lower Gulf of Thailand & 12 & 292 & 69 & 80 \\
\hline
\end{tabular}

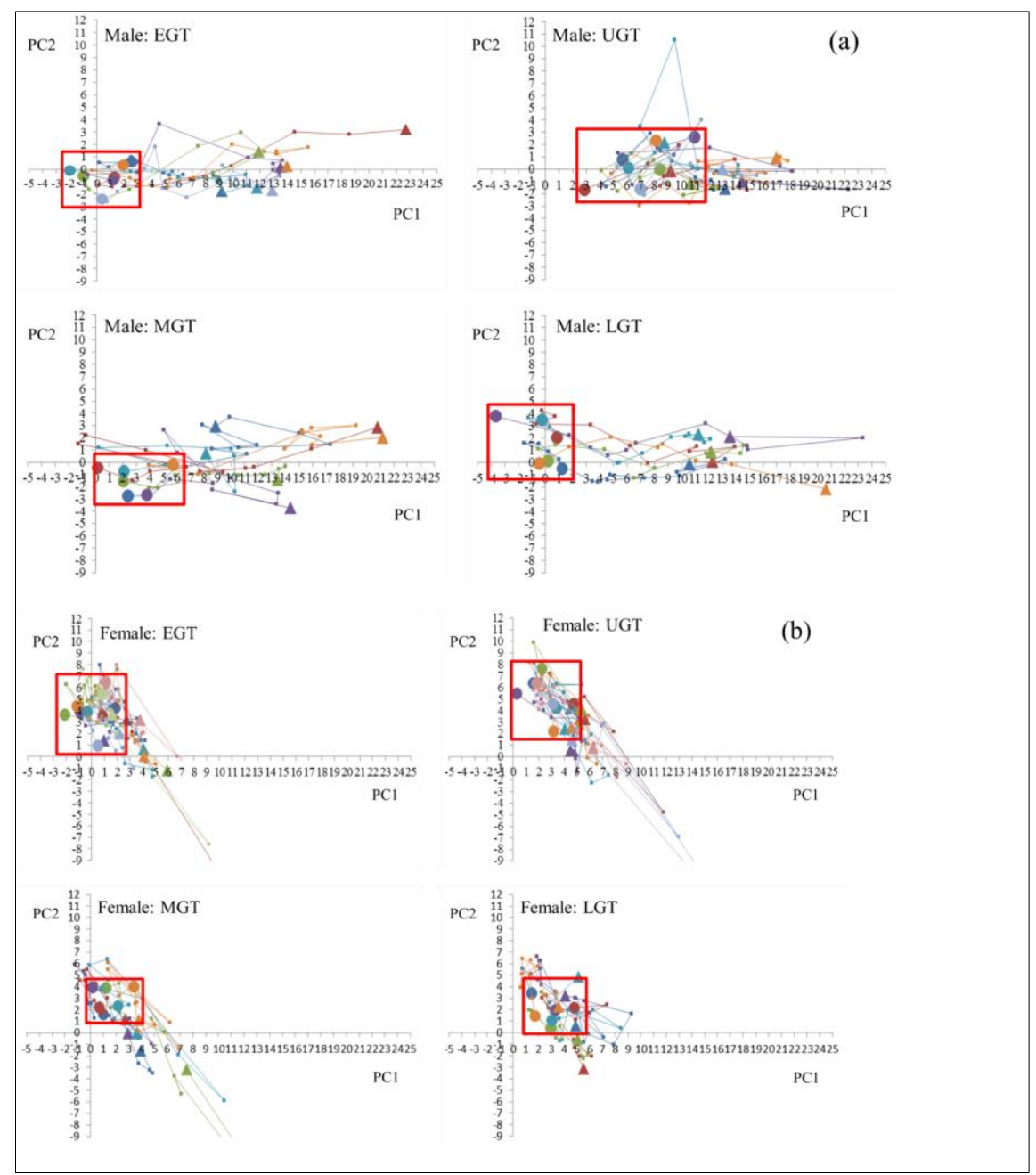

Fig. 5. Illustrations of microchemistry tracks and the percentage of residence of (a) male and (b) female Rastrelliger brachysoma in each stock within the Gulf of Thailand. Note: triangles and circles represent the spots at the primordium and edge of the otolith, respectively and the connected dots represent a single individual over time. 
otoliths (Campana, 2005; Tanner et al., 2012). However, both causes can be ruled out in this study, since each individual was estimated to reside over 50 $\%$ of its life before being captured (see Table 5); whereas the minimal error rates ( $11 \%$ for males; $14 \%$ for females) observed could be due to systematic error when measuring the concentration of microelements in some samples (Campana, 2005).

The existence of discrete adult stocks implies that short mackerel form schools and live together for more than half of their life, regardless of the original locations of the larvae. Although the major spawning area of short mackerel in the GoT was reported to be within the MGT and in scattered locations in the UGT and LGT (Maila-iad et al., 2006; Saitakon et al., 2006), the results from microchemistry element tracking, i.e. core-to-edge, of the individuals from each stock indicated that they were from different origins (Fig. 5). Srinulgray and Piyapattanakorn (2009) reported high genetic diversity of short mackerel from the same collection locations in the GoT, which implied that there is more than one spawning ground in the GoT. Another main spawning ground for short mackerel in the GoT was reported along the coast of Cambodia, which is neighbour to the EGT (Matsui, 1970; Ing, 2007).

The number of samples in this study was limited. There were at least six samples for each sex in each area, which is the minimum number for stock identification by otolith chemistry (Longmore et al., 2011). There have been a number of similar studies that managed to delineate fish stocks with small sample size; for example, Milton and Chenery (2001) used fish samples ranging from 9 to 26 individuals from various locations to detect the population structure of the shad Tenualosa ilisha (Hamilton, 1822). Also, Heidemann et al. (2012) separated the stocks of cod Gadus morhua Linnaeus, 1758 in the Baltic Sea, using the fish samples ranging from 9 to 24 individuals from different regions.

A recent genetic study indicated that some areas in the UGT might serve as spawning grounds of short mackerel in the GoT (Kongsang et al., 2016). Specifically, the spawning of short mackerel in GoT was found to be between April and May, and the larvae were in abundance between July and August (Matsui, 1970; Maila-iad et al., 2006; Saitakon et al., 2006), which is concurrent with the southwest monsoon, which drives the complex water current system in the Gulf (Sojisuporn et al., 2010). As a consequence, the movement and transport of juveniles and young fish from various spawning grounds would be affected by this complex water circulation, which mixes the larvae in a particular area before the formation of schools (Sojisuporn et al., 2010).

\section{Conclusion}

Unambiguous fish stock information can increase the efficiency of fisheries management. In this study, the LDA analyses clearly showed the presence of four stocks of short mackerel Rastrelliger brachysoma in the GoT. Further identification methods, such as analysing mitochondrial DNA (Indaryanto et al., 2015), should be conducted to confirm the findings from otolith microchemistry. Studies on life-history traits, as well as the population dynamics of each individual stock, should also be conducted to facilitate better management of short mackerel in the GoT.

\section{Acknowledgements}

The authors would like to thank the Royal Golden Jubilee Ph.D. Program of the Thailand Research Fund (PHD/0172/2554) for funding the first author's Ph.D. study. We are also grateful to Dr. Andy J. Milton and Dr. Matthew Cooper, at the National Oceanography Centre, UK, for their kind assistance.

\section{References}

Begg, G.A., Friedland, K.D., Pearce, J.B. 1999. Stock identification and its role in stock assessment and fisheries management: an overview. Fisheries Research 43:1-8. https://doi.org/10.1016/S01657836(99)00062-4

Cameron, D., Begg, G. 2004. Fisheries biology and interaction in the northern Australian small mackerel fishery. Department of Primary Industries, Brisbane. 236 pp.

Campana, S.E. 2005. Otolith elemental composition as a natural marker of fish stocks. In: Stock identification methods: Applications in fishery science, Cadrin, S.X., Friedland, K.D., Waldman, J.R. (Eds), Academic Press, New York, pp. 227-245. https://doi.org/10.1016 /B978-012154351-8/50013-7

Collette, B.B., Nauen, C.E. 1983. FAO Species Catalogue. Vol. 2. Scombrids of the world. An annotated and illustrated catalogue of tunas, mackerels, bonitos and related species known to date. Food and Agriculture Organization of the United Nations, Rome. 137 pp.

Conti, L., Grenouillet, G., Lek, S., Scardi, M. 2012. Long-term changes and recurrent patterns in fisheries landings from large marine ecosystems (1950-2004). Fisheries Research 119-120:1-12. https://doi.org/10.1016/j.fishres.2011.12.002

de Villiers, S. 1999. Seawater strontium and Sr/Ca variability in the Atlantic and Pacific oceans. Earth and Planetary Science Letters 171:623-634. https://doi.org/10.1016/S0012-821X(99)00174-0

Department of Fisheries. 2014. National management plan for marine fisheries in Thailand between 2015 and 2019. Department of Fisheries, Bangkok. 89 pp.

Elsdon, T.S., Wells, B.K., Campana, S.E., Gillanders, B.M., Jones, C.M., Limburg, K.E., Secor, D.H., Thorrold, S.R., Walther, B.D. 2008. Otolith chemistry to describe movements and life-history parameters of fishes: hypotheses, assumptions, limitations and inferences. Oceanography and Marine Biology: An Annual Review 46:297-330. https://doi.org/10.1201/9781420065756.ch7

Fishery Statistics Analysis and Research Group. 2016. The marine fisheries statistics 2011. Department of Fisheries, Bangkok. 87 pp.

Froese, R., Pauly D. 2017. http://www.fishbase.org. (Accessed 1 April 2017) 
Heidemann, F., Marohn, L., Hinrichsen, H.H., Huwer, B., Hüssy, K., Klügel, A., Böttcher, U., Hanel, R. 2012. Suitability of otolith microchemistry for stock separation of Baltic cod. Marine Ecology Progress Series 465:217-226. https://doi.org/10.3354/meps09922

Hong, P., Katayama, S.K., Yamamoto, M., Ishii, M., Baba, T., Saeki, M., Suzuki, M., Nakaya M., Yagi, Y. 2019. Comparison of age and growth of the marbled flounder Pseudopleuronectes yokohamae (Günther, $1877)$ in the coastal waters of Japan. Asian Fisheries Science 32:7280. https://doi.org/10.33997/j.afs.2019.32.02.004

Indaryanto, F.R., Imai, H., Wardiatno, Y. 2015. Genetic variation of short body mackerel, Rastrelliger brachysoma of Jawa Island, Indonesia based on mtDNA control region sequences. AACL Bioflux 8:648-855.

Ing, T. 2007. National report on the fish stocks and habitats of regional, global, and transboundary significance in the South China Sea. Fisheries Administration, Ministry of Agriculture, Forestry and Fisheries, Phnom Penh. 42 pp.

Jochum, K.P., Stoll, B. 2008. Reference materials for elemental and isotopic analyses by LA-(MC)-ICP-MS: Successes and outstanding needs. In: Laser ablation ICP-MS in the Earth sciences: Current practices and outstanding issues, Sylvester P. (Ed.), Mineralogical Association of Canada, Canada, pp. 147-168.

Kang, S., Kim, S., Telmer, K., Welch, D., Lee, Y.H. 2014. Stock identification and life history interpretation using trace element signatures in salmon otoliths. Ocean Science Journal 49:201-210. https://doi.org/10.1007/s12601-014-0020-y

Kongsang, S., Phoonsawat, R., Swatdipong, A. 2016. Population structure of short mackerel, Rastrelliger brachysoma, caught in the Upper Gulf of Thailand. In Proceedings of the 54th Kasetsart University annual conference, pp. 857-864. Bangkok, Thailand.

Koolkalya, S., Sawasdee, A., Jutagate, T. 2015. Chronicle of marine fisheries in the Gulf of Thailand: variations, trends and patterns. Indian Journal of Geo-Marine Sciences 44:1302-1309.

Liu, S., Shi, X., Yang, G., Khokiattiwong, S., Kornkanitnan, N. 2016. Distribution of major and trace elements in surface sediments of the western Gulf of Thailand: Implications to modern sedimentation. Continental Shelf Research 117:81-91. https://doi.org/10.1016 lj.csr.2016.02.002

Longmore, C., Trueman, C.N., Neat, F., O'Gorman, E.J., Milton, J.A. Mariani, S. 2011. Otolith geochemistry indicates life-long spatial population structuring in a deep-sea fish, Coryphaenoides rupestris. Marine Ecology Progress Series 435:209-224. https://doi.org /10.3354/meps/09197

Maila-iad, P., Pinputtasin, C., Sereeruk, K. 2006. Reproductive biology of chub mackerel and Indian mackerel in the upper Gulf of Thailand. Marine Fisheries Research and Development Bureau, Department of Fisheries, Bangkok. 45 pp. (in Thai).

Matsui, T. 1970. Description of the larvae of Rastrelliger (mackerel) and a comparison of the juveniles and adults of the species $R$. kanagurta and R. brachysoma. Naga Reports 5:1-33.

Methot, R.D., Wetzel, C.R. 2013. Stock synthesis: A biological and statistical framework for fish stock assessment and fishery management. Fisheries Research 142:86-99. https://doi.org/10.1016 lj.fishres.2012.10.012

Milton, D.A., Chenery, S.R. 2001. Can otolith chemistry detect the population structure of the shad hilsa Tenualosa ilisha? Comparison with the results of genetic and morphological studies. Marine Ecology Progress Series 222:239-251. https://doi.org/10.3354 Imeps222239

Moreira, C., Froufe, E., Sial, A.N., Caeiro, A., Vaz-Pires, P., Correia, A.T. 2018. Population structure of the blue jack mackerel (Trachurus picturatus) in the NE Atlantic inferred from otolith microchemistry.
Fisheries Research 197:113-122. https://doi.org/10.1016 li.fishres.2017.08.012

Morales-Nin, B. 1992. Determination of growth in bony fishes from otolith microstructure. Food and Agriculture Organization of the United Nations, Rome. 51 pp.

Morioka, S., Vongvichith, B., Marui, J., Okutsu, T., Phomikong, P., Avakul, P. and Jutagate T. 2019. Growth characteristics of two populations of Thai river sprat Clupeichthys aesarnensis (Teleostei: Clupeidae), from Laos and Thailand, with information on gonad development. Fisheries Science 85:667-675. https://doi.org /10.1007/s12562-019-01319-x

Proctor, C.H., Thresher, R.E., Gunn, J.S., Mills, D.J., Harrowfield, I.R. Sie, S.H. 1995. Stock structure of the southern bluefin tuna Thunnus maccoyii: an investigation based on probe microanalysis of otolith composition. Marine Biology 122:511-526. https://doi.org/10.1007 /BF00350674

Rasband, W.S. 2014. ImageJ. U.S. National Institute of Health, Bethesda, Maryland, USA. 198 pp.

Saitakon, T., Songkaew, N., Chotithammo, S., Vechprasit, S. 2006. Reproductive biology of short mackerel Rastrelliger brachysoma (Bleeker, 1851) and Indian mackerel R. kanagurta (Cuvier, 1817) in the Southern Gulf of Thailand. Marine Fisheries Research and Development Bureau, Department of Fisheries, Bangkok. 45 pp. (in Thai).

Shazili, N.A.M., Rashid, M.K.A., Husain, M.L., Nordin, A., Ali S. 1999. Trace metals in the surface sediments of the South China Sea, Area I: Gulf of Thailand and the East Coast of Peninsular Malaysia. In proceedings of the first technical seminar on marine fishery resources survey in the South China Sea Area I: Gulf of Thailand and East Coast of Peninsular Malaysia, pp. 73-85. Bangkok, Thailand.

Sojisuporn, P., Morimoto, A., Yanagi, T. 2010. Seasonal variation of sea surface current in the Gulf of Thailand. Coastal Marine Science 34:91-102. https://doi.org/10.1016/j.csr.2008.07.006

Srinulgray, T., Piyapattanakorn, S. 2009. Genetic diversity of short mackerel Rastrelliger brachysoma populations in the Gulf of Thailand and Andaman Sea revealed by ISSR marker. In proceedings of the 47st Kasetsart University annual conference, pp. 254-260. Bangkok, Thailand.

Sturrock, A.M., Trueman, C.N., Darnaude, A.M., Hunter, E. 2012. Can otolith elemental chemistry retrospectively track migrations in fully marine fishes? Journal of Fish Biology 81:766-795. https://doi.org /10.1111/j.1095-8649.2012.03372.x

Sturrock, A.M., Trueman, C.N., Milton, J.A., Waring, C.P., Cooper, M.J., Hunter, E. 2014. Physiological influences can outweigh environmental signals in otolith microchemistry research. Marine Ecology Progress Series 500:245-264. https://doi.org /10.3354/meps10699

Tanner, S.E., Vasconcelos, R.P., Cabral, H.N., Thorrold, S.R. 2012. Testing an otolith geochemistry approach to determine population structure and movements of European hake in the northeast Atlantic Ocean and Mediterranean Sea. Fisheries Research 125126:198-205. https://doi.org/10.1016/j.fishres.2012.02.01

Thresher, R.E., Proctor, C.H., Gunn, J.S., Harrowfield, I.R. 1994. An evaluation of electron-probe microanalysis of otoliths for stock delineation and identification of nursery areas in a southern temperate groundfish, Nemadactylus macropterus (Cheilodactylidae). Fishery Bulletin 92:817-840 